\title{
Outpatient consent practice for varicose vein surgery
}

This article was published in the following Dove Press journal:

Clinical Audit

19 December 2012

Number of times this article has been viewed

\section{Azzam Al-Amin \\ Muhammad Faiz Taib \\ Yousif Aawsaj \\ Asad Rahi}

East Lancashire Healthcare Trust, Department of Vascular Surgery, Royal Blackburn Hospital, Blackburn, United Kingdom
Correspondence: Azzam Al-Amin East Lancashire Healthcare Trust, Department of Vascular Surgery, Royal Blackburn Hospital, Haslingden Road, Blackburn, United Kingdom BB2 3HH Email azzam 187@doctors.org.uk
Background: The aims of this study were to assess the accuracy and completeness of current consent practice in an outpatient clinic for open and minimally invasive varicose vein surgery, and to ascertain the type of complications suffered by patients and their correlation with consent practice.

Methods: This was a retrospective analysis of outpatient consent practice from January to December 2010. All patients undergoing varicose vein surgery by open or endovenous laser therapy under a single consultant were identified. Case notes were examined by looking at clinic letters and consent forms, which were assessed against current standards.

Results: Over 12 months, 103 consecutive patients were analyzed, and comprised 69 undergoing open surgery and 34 undergoing endovenous laser therapy. In total, 91\% of patients were consented by a consultant, $6 \%$ by a senior house officer, and $3 \%$ by a registrar. For open surgery, all patients were consented for bruising, infection, numbness, nerve damage, and deep vein thrombosis. Only $43 \%$ were consented for pain; $2.76 \%$ were suffering pain and $6 \%$ were consented for thrombophlebitis without suffering. All patients who underwent endovenous laser therapy were consented for pain, numbness, skin discoloration, thrombophlebitis, nerve damage, and deep vein thrombosis. Only $8.8 \%$ were consented for infection and $2.9 \%$ suffered. No patients were consented for skin burns.

Conclusion: Different strategies should be considered to improve the consent process and avoid the withholding of apparently trivial but crucial information during consenting.

Keywords: consent, litigation, outpatient, varicose veins

\section{Introduction}

Varicose veins are a very common disorder, with $17 \%$ of men and $31 \%$ of women aged 35-70 years having the condition. ${ }^{1}$ Treatment options include compression hosiery, minimally invasive ablation techniques, injection sclerotherapy, and standard open surgery. In 2005-2006, 37,137 varicose vein operations were performed by the National Health Service. ${ }^{2}$ Although conventional surgery is still performed, minimally invasive procedures, such as radiofrequency ablation, endovenous laser therapy, and foam sclerotherapy are becoming increasingly popular. ${ }^{3}$

The National Institute for Health and Clinical Excellence recommends that both radiofrequency ablation and endovenous laser therapy may be used, with normal arrangements for clinical governance, consent, and audit. ${ }^{4}$ The General Medical Council consent guidelines also stipulate the information that patients should be given during the consent process. ${ }^{5}$ 
In 1997 it was estimated that 30-40 patients per year initiated legal action in connection with varicose vein treatment, ${ }^{6}$ highlighting the fact that this is a potentially litigious area and care must be taken when consenting patients for varicose vein surgery.

In August 2009, the National Health Service Centre for Evidence-based Purchasing published a review of 18 papers comparing endovascular techniques with conventional surgery, ${ }^{7}$ and produced a methodical list of reported complications for endovenous laser therapy and open surgery. In this study we used that list to check whether the consent taken by our surgeons included all complications (Table 1). The aim of this research was to evaluate the consent process for varicose vein surgery over a 12 -month period at our trust. We also sought to determine the types of complications suffered by patients and their correlation with consent practice.

\section{Materials and methods}

In this retrospective study, all adult patients undergoing open varicose vein surgery and endovenous laser therapy from January to December 2010 inclusive under a single consultant were identified at our Trust. Case notes were retrieved and the consent forms were analyzed. This was done via the clinical governance department at the Trust. A proforma was designed to collect data including age, type of surgery, American Society of Anesthesiologists grade, Clinical Severity, Etiology, Anatomy and Pathophysiology classification (Table 3), grade of consenter, complications consented for, and complications suffered by the patients.

\section{Results}

One hundred and ten patients were identified from the Trust database. Of these, 103 case notes were identified. There were 42 males and 61 females, of mean age 48.4 (range 20-94) years. Thirty-four patients underwent endovenous laser therapy and 69 underwent open surgery. For open surgery, 48 were primary high-tie procedures, eight were high-tie redo operations, five were high-tie and saphenopopliteal ligations, six were primary saphenopopliteal ligations only, and two were saphenopopliteal redo operations (Table 2). Ninety-nine were day-case procedures and four required an inpatient stay. One hundred and one patients were consented in the outpatient clinic, whilst two patients were consented on the day of the procedure. Eighty-two percent of the endovenous laser therapy patients and $83 \%$ of the open surgery patients were provided with an EIDO information leaflet. Clinical Severity, Etiology, Anatomy and Pathophysiology classifications and American Society of Anesthesiologists grades for the patients
Table I Specific complications of varicose vein surgery, adapted from National Health Service Centre for Evidence-based Purchasing $09017^{7}$ and National Institute for Health and Clinical Excellence guidelines $2004^{4}$

\begin{tabular}{ll}
\hline Open surgery & Endovenous laser therapy \\
\hline Bruising & Pain \\
Pain & Numbness \\
Numbness & Skin discoloration \\
Nerve injury & Thrombophlebitis \\
Wound infection & Nerve injury \\
Thrombophlebitis & Skin burns \\
Deep vein thrombosis & Deep vein thrombosis \\
\hline
\end{tabular}

are shown in Tables 3 and 4. The results of consenting for the various complications are summarized in Table 5 for both open surgery and endovenous laser therapy, and show that the majority of potential complications were consented for. The grades of consenters are shown in Figure 1. We also investigated the complications actually suffered by the patients and whether or not they were consented for these complications (Tables 6 and 7). Table 6 shows that not all patients scheduled for open surgery were consented for pain and bruising. This is relevant because some of these patients went on to experience these complications. Likewise, Table 7 shows that not all patients scheduled for endovenous laser therapy were consented for bruising and infection.

\section{Discussion}

Our results show that the majority of potential complications of endovenous laser therapy and open surgery (as found in the National Health Service Centre for Evidence-based Purchasing review) were consented for. However, certain important complications were omitted from some consent forms. These factors can lead to patient dissatisfaction and result in litigation. ${ }^{8}$

This study highlights areas amenable to improvement. It shows that some known complications of varicose vein surgery were not consented for, and this can lead to patient dissatisfaction if the patient suffers from a complication. Importantly, not all patients scheduled for open surgery were consented for postoperative pain and bruising, but a propor-

Table 2 Types of varicose vein surgery performed in our study

\begin{tabular}{ll}
\hline Type of surgery & Patients (n) \\
\hline Primary high-tie & 48 \\
Revision high-tie & 8 \\
High-tie and saphenopopliteal ligations & 5 \\
Primary saphenopopliteal ligations & 6 \\
Revision saphenopopliteal ligations & 2 \\
Endovenous laser therapy & 34 \\
\hline
\end{tabular}


Table 3 Clinical Severity, Etiology, Anatomy and Pathophysiology classification

\begin{tabular}{lll}
\hline Classification & Description & Patients (n) \\
\hline C0 & $\begin{array}{l}\text { No evidence of venous disease } \\
\text { Superficial spider veins } \\
\text { (reticular veins) only }\end{array}$ & 0 \\
C2 & $\begin{array}{l}\text { Simple varicose veins only } \\
\text { Ankle edema of venous origin } \\
\text { C3 }\end{array}$ & $\begin{array}{l}\text { (not foot edema) } \\
\text { Skin pigmentation in gaiter }\end{array}$ \\
C4 & area (lipodermatosclerosis) & 14 \\
C5 & Healed venous ulcer & 4 \\
C6 & Open venous ulcer & 0 \\
\hline
\end{tabular}

tion of patients did suffer from these side effects. Further, only $6 \%$ scheduled for open surgery were consented for thrombophlebitis. One patient (2.9\%) scheduled for endovenous laser therapy suffered a postoperative infection, and was not consented with this complication.

Ninety-one percent of patients scheduled for open surgery or endovenous laser therapy were consented by a consultant. This may partly explain why overall the consent was accurate. Ninety-eight percent of patients were consented in the outpatient clinic, which provides a more suitable environment and adequate time for patient discussion than the situation immediately prior to surgery.

Although not a major complication, we would suggest that all patients, whether scheduled for open surgery or endovenous laser therapy, are consented for thrombophlebitis. Although this is usually a relatively minor condition that is self-limiting, it can cause undue concern to patients. None of the patients scheduled for endovenous laser therapy were consented for skin burns, but this has been shown to be a potential complication in the literature. ${ }^{9}$

Four of $69(5.8 \%)$ patients scheduled for open surgery suffered minor groin wound infections. These did not require admission to hospital, and were treated via primary care or an outpatient prescription. One patient $(2.9 \%)$ of 34 scheduled for endovenous laser therapy suffered a minor wound infection that resolved quickly.

Table 4 American Society of Anesthesiologists grade

\begin{tabular}{ll}
\hline ASA grade & Patients (n) \\
\hline 1 & 57 \\
2 & 39 \\
3 & 5 \\
4 & 0 \\
5 & 0 \\
Unknown & 2 \\
\hline
\end{tabular}

Abbreviation: ASA, American Society of Anesthesiologists.
Table 5 Complications consented for surgery

\begin{tabular}{llllll}
\hline Complication & \multicolumn{2}{l}{$\begin{array}{l}\text { Open surgery } \\
\text { consented }\end{array}$} & & \multicolumn{2}{l}{$\begin{array}{l}\text { EVLT } \\
\text { consented }\end{array}$} \\
\cline { 2 - 3 } & Yes & No & & Yes & No \\
\hline Bruising & 64 & 5 & & 27 & 7 \\
Pain & 30 & 39 & & 34 & 0 \\
Numbness & 60 & 9 & & 27 & 7 \\
Thrombophlebitis & 4 & 65 & & 33 & $\mathrm{I}$ \\
Nerve injury & 40 & 29 & & $\mathrm{n} / \mathrm{a}$ & $\mathrm{n} / \mathrm{a}$ \\
Infection & 64 & 5 & & 3 & 31 \\
Deep vein thrombosis & 61 & 8 & & 34 & 0 \\
Recurrence & 63 & 6 & & 28 & 6 \\
Skin burns & $\mathrm{n} / \mathrm{a}$ & $\mathrm{n} / \mathrm{a}$ & & 0 & 34 \\
Skin discoloration & $\mathrm{n} / \mathrm{a}$ & $\mathrm{n} / \mathrm{a}$ & & 19 & 15 \\
\hline
\end{tabular}

Abbreviation: EVLT, endovenous laser therapy.

We would suggest using preprinted specific consent forms for the various types of varicose vein surgery. These should be updated at regular intervals. They may be difficult to produce in all centers, and may have to be standardized nationally. In our study, the rates of grade of consenter were the same for both endovenous laser therapy and open surgery. The large majority of patients were consented by the consultant in the outpatient clinic. The consent process may be a useful training opportunity for the supervisor and the trainee. The authors suggest a consent form template be used, as shown in Appendix 1.

Finally, the vast majority of patients were provided with an EIDO information leaflet which does cover all complications. This is an important step in patient education and minimizes confusion. It also gives the patient time to

\section{Grade of consenter}

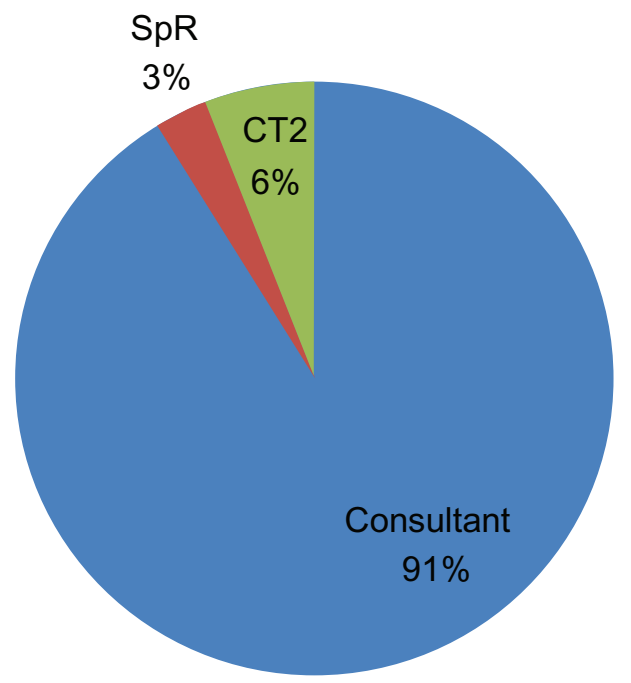

Figure I Grade of consenter (open surgery and endovenous laser therapy). 
Table 6 Open surgery: complications consented for versus those suffered from

\begin{tabular}{llll}
\hline Complication & $\begin{array}{l}\text { \% overall } \\
\text { consent }\end{array}$ & \% suffered & $\begin{array}{l}\text { \% sufferers } \\
\text { consented }\end{array}$ \\
\hline Bruising & 93 & 3.5 & 80 \\
Pain & 43 & 2.8 & 25 \\
Numbness & 87 & 2.0 & 100 \\
Thrombophlebitis & 6 & 0 & $\mathrm{n} / \mathrm{a}$ \\
Nerve injury & 58 & 0 & $\mathrm{n} / \mathrm{a}$ \\
Infection & 93 & 5.8 & 100 \\
Deep vein thrombosis & 88 & 0 & $\mathrm{n} / \mathrm{a}$ \\
Recurrence & 91 & 1.4 & 100 \\
\hline
\end{tabular}

gain an understanding of the procedure that they have been consented for. Provision of an information leaflet can be documented on the consent form.

There were several limitations to this audit. Importantly, it was retrospective, which can lead to inaccuracies as a result

Table 7 Endovenous laser therapy: complications consented for versus suffered those from

\begin{tabular}{llll}
\hline Complication & $\begin{array}{l}\text { \% overall } \\
\text { consent }\end{array}$ & \% suffered & $\begin{array}{l}\text { \% sufferers } \\
\text { consented }\end{array}$ \\
\hline Bruising & 79 & $1 \mathrm{I}$ & 75 \\
Pain & 100 & 24 & 100 \\
Numbness & 79 & 2.9 & 100 \\
Thrombophlebitis & 97 & 2.9 & 100 \\
Infection & 8.8 & 2.9 & 0 \\
Deep vein thrombosis & 100 & 0 & $\mathrm{n} / \mathrm{a}$ \\
Skin burns & 0 & 0 & $\mathrm{n} / \mathrm{a}$ \\
Skin discoloration & 56 & 2.9 & 100 \\
Recurrence & 82 & 5.8 & 100 \\
\hline
\end{tabular}

of missing or incomplete data in patient case notes. Further, we only audited the practice of one consultant, and it would be a useful exercise to reaudit the consenting of all surgeons performing varicose vein surgery in our Trust. The sample size was relatively small, and a larger one might produce more accurate results. In conclusion, complications that arise and are not routinely consented for must be recorded in order to update our consent forms to comply with evidence-based practice.

\section{Disclosure}

The authors report no conflicts of interest in this work.

\section{References}

1. Franks PJ, Wright DD, Moffatt CJ, et al. Prevalence of venous disease: a community study in west London. Eur J Surg. 1992;158:143-147.

2. Department of Health. Hospital Episode Statistics 2005-2006. London, UK: Department of Health; 2006. Available from: http://www.hesonline. nhs.uk.

3. Nijsten T, van den Bos RR, Goldman MP, et al. Minimally invasive techniques in the treatment of saphenous varicose veins. $J$ Am Acad Dermatol. 2009;60:110-119.

4. The National Institute for Health and Clinical Excellence. Endovenous laser treatment of the long saphenous vein: guidance 2004. Available from: http://publications.nice.org.uk/endovenous-laser-treatment-of-thelong-saphenous-vein-ipg52/. Accessed November 12, 2012.

5. General Medical Council. Good Medical Practice Guidelines, November 2006 (updated March 2009). Available from: http://www.gmc-uk.org.

6. Scurr JRH, Scurr JH. Varicose veins: a review of 200 medicolegal claims. Clin Risk. 2005;11:225-230.

7. Centre for Evidence-Based Purchasing. 09017. August 2009. Available from: http://nhscep.useconnect.co.uk/CEPProducts/Catalogue.aspx.

8. Tennant WG, Ruckley CV. Medicolegal action following treatment for varicose veins. Br J Surg. 1996;83:291-292.

9. Johnson CM, McLafferty RB. Endovenous laser ablation of varicose veins: review of current technologies and clinical outcome. Vascular. 2007; 15:250-254. 
Appendix I Proposed consent for open surgery and endovenous laser therapy

Proposed consent for open surgery

Frequent: bruising, pain, scarring, thrombophlebitis

Rare: numbness, nerve injury, infection, deep vein thrombosis, recurrence

Not severe: bruising, pain, scarring, thrombophlebitis, infection, numbness

Potentially severe: nerve injury, deep vein thrombosis

Proposed consent for endovenous laser therapy

Frequent: bruising, pain, skin discoloration, thrombophlebitis

Rare: skin burns, numbness, deep vein thrombosis, infection, recurrence

Not severe: bruising, pain, skin discoloration, thrombophlebitis, infection, skin burns, numbness

Potentially severe: deep vein thrombosis

Clinical Audit

\section{Publish your work in this journal}

Clinical Audit is an international, peer-reviewed, open access journal focusing on the processes and outcomes of clinical audit in any area of healthcare. All aspects of patient care are addressed within the journal and practitioners from all disciplines are invited to submit their work. Areas covered include: Publication of audits; How an audit has changed practice;

Submit your manuscript here: http://www.dovepress.com/clinical-audit-journal
Dovepress

Practical tips on how to do audits and to avoid pitfalls; How audits have changed patient care; Calls and justifications for new audits. The manuscript management system is completely online and includes a very quick and fair peer-review system, which is all easy to use. Visit http://www.dovepress. com/testimonials.php to read real quotes from published authors. 